\title{
In vivo model of human post-traumatic heterotopic ossification demonstrates early fibroproliferative signature
}

\author{
Jaira F. de Vasconcellos ${ }^{1,2+} \mathbb{C D}^{\text {, Sonia Zicari }}{ }^{1,2+}$, Stephen D. Fernicola ${ }^{1}$, Daniel W. Griffin ${ }^{1}$, Youngmi Ji', \\ Emily H. Shin ${ }^{1}$, Patrick Jones ${ }^{1}$, Gregory T. Christopherson ${ }^{1}$, Husain Bharmal' ${ }^{1}$ Carl Cirino ${ }^{1}$, Thao Nguyen ${ }^{3}$, \\ Astor Robertson ${ }^{3}$, Vincent D. Pellegrini Jr. ${ }^{4}$ and Leon J. Nesti ${ }^{1,5^{*}}$
}

\begin{abstract}
Background: The relationship between the tissue injury healing response and development of heterotopic ossification $(\mathrm{HO})$ is poorly understood. Here we compare a rat blast model and human traumatized muscle from a blast injury to study the early signatures of osteogenesis and fibrosis during the formation of $\mathrm{HO}$.

Methods: Rat and human tissues were characterized using histology, scanning electron microscopy, immunohistochemistry, as well as gene and protein expression analysis. Additionally, animals and humans were assessed radiographically for $\mathrm{HO}$ formation following injury.

Results: Markers of bone formation were dramatically increased in tissue samples from both humans and rats, and both displayed increased fibroproliferative regions within the injured tissues and elevated expression of markers of tissue fibrosis such as TGF- $\beta 1$, Fibronectin, SMAD3 and PAI-1. Markers of inflammation and fibrosis (ACTA, TNFa, BMP1 and $B M P 3$ ) were elevated at the RNA level in both rat and human samples. By day 42 , bone formation in the rat blast model appeared similar in radiographs compared to human patients who progressed to develop post-traumatic HO.

Conclusions: Our data demonstrates that a similar early fibrotic response is evident in both the rat blast model and the human tissues following a traumatic injury and demonstrates the relevance of this animal model for future translational studies.
\end{abstract}

Keywords: Heterotopic ossification, HO, Rat blast model, Fibrosis

\section{Background}

Human musculoskeletal injury is commonly associated with trauma and is followed by either a robust healing response involving tissue regeneration or fibrosis [1-4]. In many instances, for example, this healing program results in the creation of functional tissue (e.g. muscle and/or bone regeneration) or can result in the formation of scar tissue [1-4]. In some situations, following muscle

\footnotetext{
*Correspondence: leonnesti@gmail.com; leon.nesti@usuhs.edu; leon.j.nesti.mil@mail.mil

†Jaira F. de Vasconcellos and Sonia Zicari contributed equally to this work

${ }^{5}$ Department of Surgery, Uniformed Services University of the Health

Sciences, 4301 Jones Bridge Road, Room A3008C, Bethesda, MD

20892-8022, USA

Full list of author information is available at the end of the article
}

trauma, such as that observed in recent wartime wounds, the healing response may lead to aberrant bone formation in the soft tissues, which is termed heterotopic ossification $(\mathrm{HO})$ [5-7]. The incidence of ectopic bone formation following musculoskeletal injury (post-traumatic $\mathrm{HO}$ ) is a relatively infrequent event but it becomes more common with higher energy injuries and with concomitant central nervous system trauma $[8,9]$. Post-traumatic $\mathrm{HO}$ is now known to be a common event following musculoskeletal injury sustained in modern combat [10-13]. There is a documented incidence of approximately $60 \%$ among high-energy blast-injured patients wounded during the recent war efforts in Iraq and Afghanistan [1013]. Post-traumatic $\mathrm{HO}$ is a significant complication and it is often associated with pain, skin breakdown, impaired 
prosthetic fitting, decreased joint range-of-motion, neurovascular compromise and ultimately a dysfunctional outcome, culminating in a poor quality of life $[7,12,14$, 15].

Currently, the molecular basis leading to $\mathrm{HO}$ remains unclear and there are no universally acceptable interventions for disease prevention. Further, it is not possible to correctly predict which patients surviving blast-injuries will develop $\mathrm{HO}$; thus, there is an unmet need to better understand the molecular mechanisms leading to the onset of $\mathrm{HO}$, to develop predictive biomarkers, novel treatment options and preventive strategies. To more thoroughly understand the process by which $\mathrm{HO}$ forms, we have utilized a previously described and validated rat blast injury model that appears to reproduce the pathologic factors necessary for the development of post-traumatic HO in the blast-injured limb [16-18]. In this model, Sprague-Dawley rats develop $\mathrm{HO}$ in the residual limb following extremity blast amputation without addition of any exogenous osteogenic agents. The development of disease in the rat model closely mimics the human pathology of HO [16]. The goal of this study was to demonstrate similarities in the early cellular and molecular markers that may lead to $\mathrm{HO}$ formation between the in vivo HO rat blast model and human traumatized muscle from patients following blast injury who progressed to develop HO. In particular, we have focused on the role of the fibrotic response as a prelude to bone formation in both humans and the rat model, given the strong link between fibrosis and bone development in HO [19-23]. The results presented here should provide substantial justification for using this rat blast model to gain a better understanding of $\mathrm{HO}$ pathogenesis and lead to the identification of predictive biomarkers for posttraumatic $\mathrm{HO}$ and novel therapeutic strategies.

\section{Methods}

\section{Rat blast model and tissue collection}

Using a previously described hind limb rat protocol, Sprague-Dawley rats $(n=8)$ were first anesthetized with ketamine $(80 \mathrm{mg} / \mathrm{kg})$ and xylazine $(7 \mathrm{mg} / \mathrm{kg})$ delivered intraperitoneally, and pre-blast doses of enrofloxacin $(5 \mathrm{mg} / \mathrm{kg})$ and buprenorphine $(0.05 \mathrm{mg} / \mathrm{kg})$ were administered subcutaneously for antisepsis and analgesia, respectively, as previously described [16]. Animals were then secured to an aluminum block with a $2.5 \mathrm{~cm}$ hole. The limb to be traumatically amputated was held in place over this hole [16]. Immediately afterwards, these injured rats were transferred to sterile field for wound management and primary surgical closure. A detailed description of the blast setup, blast, surgical closure and post blast care has been previously reported [16]. Four rats were sacrificed at 7 days post-injury and the tissue was collected for analysis. Under sterile conditions, muscle samples $\left(\sim 0.2 \mathrm{~cm}^{3}\right)$ from the zone of the injury of the traumatized residual limb of the rats were surgically removed and analyzed as detailed below. Control uninjured muscle tissue RNA was harvested from uninjured lower extremities. In the acute post-operative period, rats were monitored for signs of distress, and given a 5-day course of buprenorphine $(0.05 \mathrm{mg} / \mathrm{kg}$ administered subcutaneously twice a day) and enrofloxacin $(5 \mathrm{mg} / \mathrm{kg}$ administered subcutaneously twice a day). All remaining animals $(n=4)$ were euthanized 42 days after the blast injury, to be used for radiographic evaluation of the injury site. Radiographs of the amputated limbs were performed with a digital Faxitron radiography machine (Faxitron X-Ray LLC, Lincolnshire, IL) as previously described [16]. All animal procedures were performed under approved appropriate protocols by the Institutional Animal Care and Use Committee at the University of Maryland Medical Center.

\section{Human tissue collection and radiographs}

Discarded muscle tissues $\left(\sim 0.2 \mathrm{~cm}^{3}\right.$ in volume) were obtained from the zone of injury of extremities from 5 wounded patients during surgical debridement procedures within 2-weeks of blast trauma (average 10-days post-injury). Tissue samples were divided into equal portions for histology and RNA extraction. This collection method was performed with patient consent according to a protocol approved by the Institutional Review Board at Walter Reed National Military Medical Center. Human control uninjured muscle tissue RNA was purchased from Amsbio (Cambridge, MA). Human radiographs of the injured extremity were performed following standard clinical protocols at the Walter Reed National Military Medical Center as part of the patient's clinical care, including in preparation for the debridement procedure (average 10-days post-injury) and 42 days after injury, and evaluated by independent orthopaedic surgery residents under the direct supervision of at least one experienced orthopaedic surgeon.

\section{Total RNA extraction from traumatized tissues, quantitative reverse transcription-polymerase chain reaction (qRT-PCR) and common cytokine PCR array}

Total RNA from rat $(\mathrm{n}=4,7$-days post-injury) and human ( $\mathrm{n}=5$, average 10 -days post-injury) blast injured tissues were prepared using the RNeasy mini Kit (Qiagen, Germantown, MD) following manufacturer's instruction and as previously described [24]. $500 \mathrm{ng}$ of total RNA from each sample was converted into complementary DNA (cDNA) using the Superscript III First Strand Synthesis System for RT-PCR (Invitrogen/Thermo Fisher Scientific, Carlsbad, CA). To investigate common genes 
related to osteogenesis and fibrosis between human and rat, real-time qRT-PCR was performed using commercially available TaqMan gene expression assays (Applied Biosystems/Thermo Fisher Scientific, Foster City, CA) for OPN, RUNX2 and COL1A1 (human samples) as well as Opn, Runx2 and Colla1 (rat samples). Gene expression was normalized to HPRT1 (human samples) and Hprt1 (rat samples) levels, and relative gene expression was determined using the $2^{-\Delta \Delta C t}$ method [25]. For the cytokine gene expression profiles, RNA integrity was assessed electrophoretically using a 6000 RNA Pico labon-a-chip in a Bioanalyzer (Agilent, Santa Clara, CA), and cDNA was synthesized using the $\mathrm{RT}^{2}$ First Strand Kit (SA Biosciences/Qiagen). PCR arrays were performed with a $\mathrm{RT}^{2}$ Profiler ${ }^{\mathrm{TM}}$ PCR Array Rat Common Cytokines (cat\# PARN-021Z, SA Biosciences/Qiagen) and $\mathrm{RT}^{2}$ Profiler $^{\mathrm{TM}}$ PCR Array Human Common Cytokines (cat\# PAHS-021Z, SA Biosciences/Qiagen) following manufacturer's instructions, and data analysis was performed using the $\mathrm{RT}^{2}$ Profiler PCR Array Data Analysis software (SA Biosciences/Qiagen). All PCR-based assays were performed using an ABI7900HT system (Applied Biosystems/Thermo Fisher Scientific).

\section{Histology and picrosirius red (PSR) staining}

Both sets of rat and human traumatized tissue and uninjured control tissue samples were separately fixed in phosphate-buffered 4\% paraformaldehyde (FD Neuro Technologies Inc, Columbia, MD) followed by sequential ethanol dehydration infiltrated with xylenes and embedded in paraffin as previously described [24]. Five-micron thick sections on glass slides from all tissues were used for hematoxylin and eosin (H\&E) and Picrosirius Red (PSR) staining for histo-pathological evaluation and collagen immunohistochemistry, respectively. Sections were deparaffinized in xylenes, rehydrated using a graded series of ethanol and stained with H\&E staining following standard laboratory procedures and PSR for $1 \mathrm{~h}$ as previously described $[24,26]$. Stained $H \& E$ slides were analyzed in bright-field microscopy and stained PSR slides were analyzed by polarizing microscopy following standard procedures.

\section{Scanning electron microscopy (SEM)}

Approximately $5 \mathrm{~mm}^{3}$ pieces of both traumatized rat and human tissues were decellularized in 1\% SDS solution for $30 \mathrm{~min}$ at $37{ }^{\circ} \mathrm{C}$. Samples were fixed in $2.5 \%$ paraformaldehyde (PFA)/glutaraldehyde in $0.1 \mathrm{M}$ sodium cacodylate buffer ( $\mathrm{pH}$ 7.4; Electron Microscopy Sciences, Hatfield, PA) overnight at $4{ }^{\circ} \mathrm{C}$. Fixed tissues were incubated with 1\% osmium tetroxide (Electron Microscopy Sciences) for $20 \mathrm{~min}$ and dehydrated in a graded ethanol $(25 / 50 / 75 / 85 / 95 / 100 \%)$ and hexamethyldisilazane
(HMDS; Electron Microscopy Sciences) (25/50/75/100\%). Samples were vacuum dried at room temperature. The desiccated samples were coated with gold using a sputter coater (Balzers; Schaumburg, IL) and surface topography was examined by scanning electron microscope (S-4800; Hitachi, Troy, MI, in the Biomedical Engineering and Physical Science Shared Resource, NIBIB, NIH) at $5 \mathrm{kV}$ with various magnifications.

\section{Immunohistochemistry-immunofluorescence (IHC-IF)}

Paraformaldehyde fixed $5-\mu \mathrm{m}$ thick tissue sections on glass slides underwent deparaffination and hydration and antigen retrieval. Primary antibodies used were Transforming Growth Factor- $\beta 1$ (TGF- $\beta 1$ ) and CD31 (Abcam, Cambridge, MA). After primary antibody incubation, the sections were washed 3 times with phosphate-buffered saline (PBS) for $5 \mathrm{~min}$. The sections were than incubated with each respective secondary antibody (Alexa Fluor 488, Alexa Fluor 568-tagged secondary mouse or rabbit IgG antibodies, Invitrogen/Thermo Fisher Scientific, 1:250) for $30 \mathrm{~min}$ at room temperature. After secondary antibody incubation, Hoechst $33342(1 \mu \mathrm{g} / \mathrm{ml})$ was applied for $5 \mathrm{~min}$ onto section for nuclear staining. The sections were then washed 3 times in PBS for 5 min each and mounted in FluorSave reagent (Calbiochem, Billerica, MA). Slides with stained sections were viewed and analyzed using a Zeiss Axio Observer Z1 with Apotome optical sectioning device (Carl Zeiss, Thornwood, NY).

\section{Western blot analysis}

Rat ( $\mathrm{n}=4,7$-days post injury) and human $(\mathrm{n}=5$, average 10-days post-injury from $\mathrm{HO}$ patients) traumatized tissues were homogenized in RIPA Buffer (Sigma-Aldrich, St. Louis, MO) containing protease inhibitors (Roche, South San Francisco, CA). Total protein extracts were centrifuged at $13,000 \mathrm{rpm}$ for $15 \mathrm{~min}$ at $4{ }^{\circ} \mathrm{C}$, and the supernatants used for downstream analyses. Control uninjured human muscle tissue lysate was purchased from Abcam (Cambridge, MA) and control rat tissue was obtained from the lower uninjured extremities of Sprague-Dawley rats not exposed to blast injury. $10 \mu \mathrm{g}$ of total protein extracts were separated by gel electrophoresis using a NuPAGE ${ }^{\circledR} 4-12 \%$ Bis-Tris Gel (Applied Biosystems/Life Technologies, Carlsbad, CA). Proteins were then transferred onto Immobilon-P membranes (Millipore, Burlington, MA) and stained with Ponceu $\mathrm{S}$ solution (Sigma-Aldrich) to assess transfer efficiency. Membranes were incubated with the indicated antibodies: Fibronectin (FN), SMAD family member 3 (SMAD3), TGF- $\beta 1$, Plasminogen Activator Inhibitor 1 (PAI-1) and Glyceraldehyde-3-Phosphate Dehydrogenase (GAPDH) as loading control. Detection was performed by incubation with horseradish peroxidase-conjugated mouse or 
rabbit secondary antibodies (KPL, Gaithersburg, MD; 1:10,000) followed by Immobilon Western Chemiluminescent HRP Substrate Kit (Millipore).

\section{Statistical analysis}

Replicates are expressed as mean \pm SD values and significance was calculated by two-tailed Student's t-test.

\section{Results}

\section{Comparisons between rat and human traumatized tissues by radiographs and $q \mathrm{RT}-\mathrm{PCR}$}

Recently a rat model has been developed for the formation of traumatic injury-induced HO [16]. Here we sought to examine this model in more detail to determine if morphological, molecular and biochemical similarities existed between traumatized rat and human muscle tissue, specifically focusing on an early fibrotic response. Radiographic analysis demonstrated radio-opaque densities outside the cortical boundaries of the normal skeleton consistent with $\mathrm{HO}$ form in both rat (Fig. 1, left panels) and human (Fig. 1, right panels) traumatized tissues. At 7-days post-injury, soft tissue mineralization is evident and these opacities become larger and denser over the 42 days healing period in rat traumatized tissues. Similarly, in human HO, formation of soft tissue mineralization appears at 10-days post-injury and this opacity increases in size and density by 42 days (Fig. 1).

We next performed qRT-PCR analysis on RNA isolated from $\mathrm{HO}$ rat and human tissues to assess the expression of genes associated with early bone formation at 7- to 10-days post-trauma. We detected significant increases $(\mathrm{p}<0.01$, as evaluated with Student's $t$-test) in the expression of the osteogenic markers Osteopontin (Opn and $O P N)$, Runt-related Transcription Factor 2 (Runx2 and RUNX2), and Type 1 Collagen (Colla1 and COL1A1) in the injured tissues compared to the levels expressed in uninjured control tissues (Fig. 2). This data indicates that the post-blast injured tissues of the rat demonstrate early signs of bone formation nearly identical to that evident in human HO.

\section{Early histo-pathological comparison between rat and human traumatized tissues demonstrates similar fibrotic development}

Hematoxylin and Eosin staining revealed that at $7-$ to 10-days after blast injury, both rat and human tissue exhibited similar patterns of hypercellularity, inflammation and fibrotic hyperplasia (Fig. 3, FP; Fibroproliferative Region, NF; Normal Fiber). Destruction of the normal muscle architecture with fibrous stroma replacing muscle fibers was evident. This hypercellular fibroproliferative response is consistent with that previously reported for the histopathology of human HO tissue samples [24, 27].

We next used picrosirus red (PSR) to stain intramuscular fibrosis. PSR preferentially binds fibrotic collagen fibers (collagens I and III) [26], appearing red under unfiltered light microscopy but also shows enhanced birefringence under polarized light. Both rat and human uninjured control muscle exhibit minimal PSR staining under both bright-field and polarizing conditions (Fig. 4 top panels). However, in the 7 - to 10-days post-blast injured tissues there is robust PSR staining within the muscle fibers (Fig. 4, bottom panels), indicating elevated collagen fibril deposition.

As an additional method to assess the underlying fibrotic tissue, the injured rat and human muscle was decellularized and processed for scanning electron microscopy. As shown in Fig. 5, the rat and human tissues show a random array of fibers on the order of $100 \mathrm{~nm}$ in diameter, consistent with collagen fibrils [28-30], and their arrangement are nearly identical in both samples.

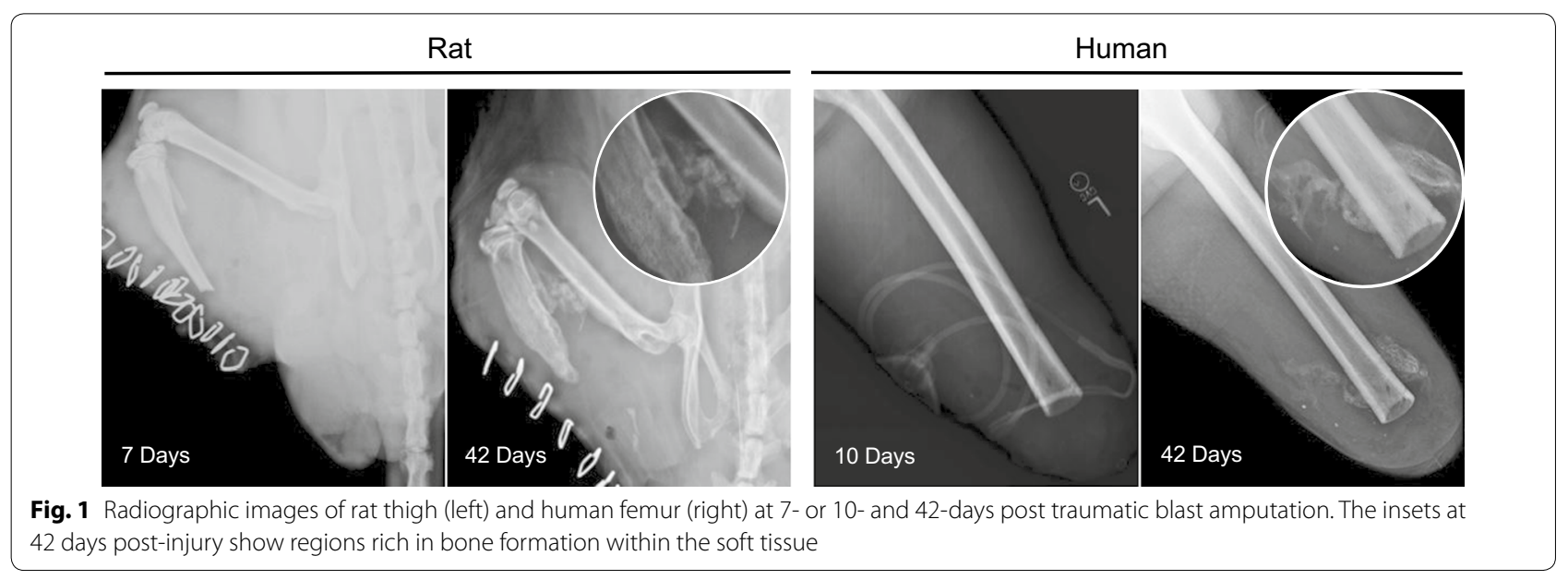




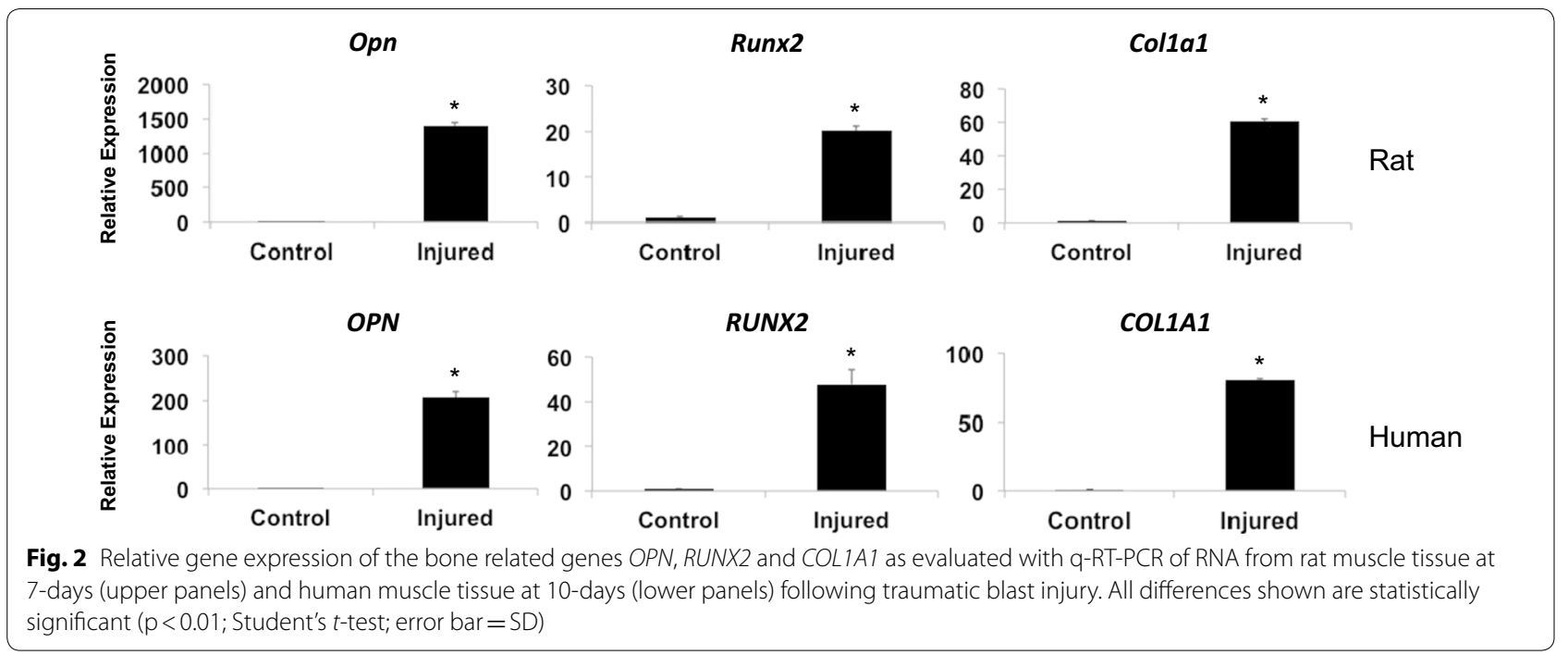

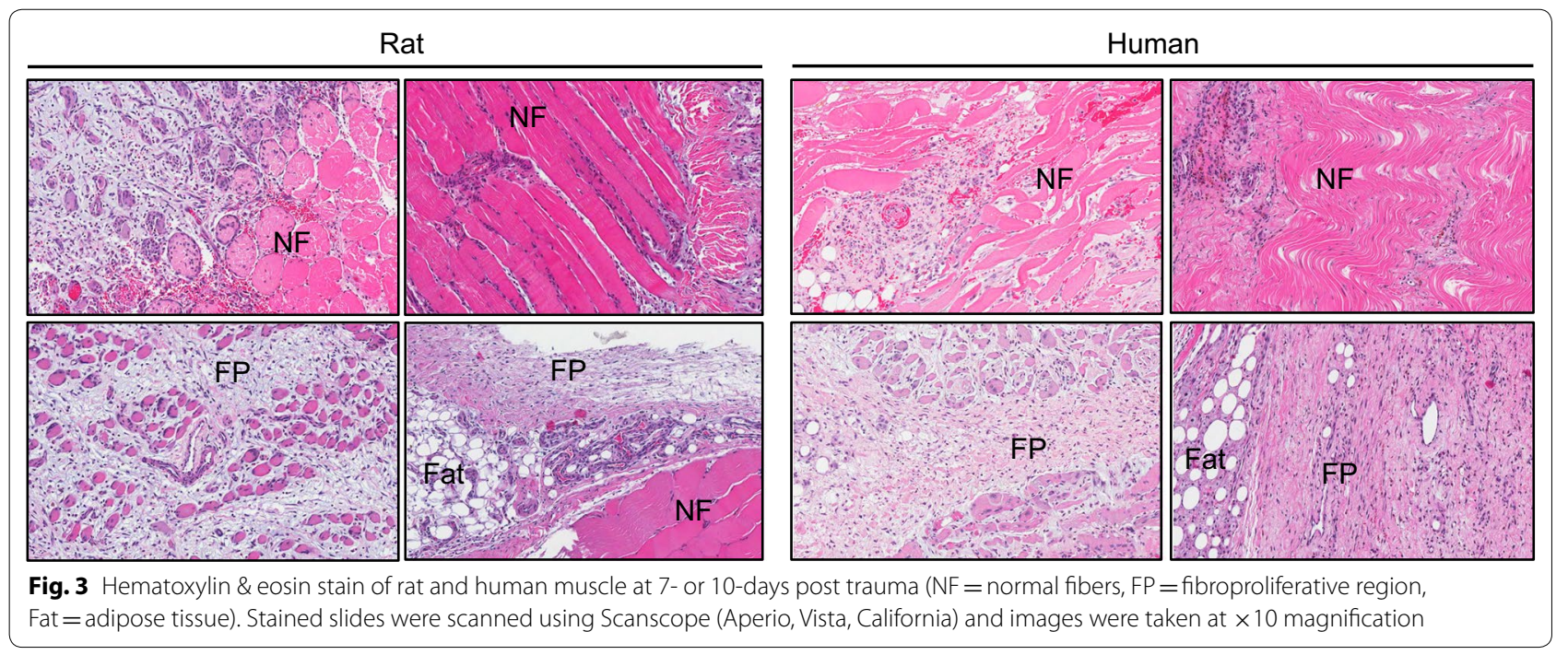

Given that an overt fibrotic response dominates these traumatic wounds, it would be expected that mediators of fibrosis, such as TGF- $\beta$ family members, would be elevated within the wound area. One such factor, TGF$\beta 1$, has been shown to be elevated in HO tissues [24, 31 . We therefore looked at TGF- $\beta 1$ levels in rat tissues (7-days) and in human tissues (average 10-days) after traumatic injury. As shown in the immunofluorescence in Fig. 6, it is evident that the injured rat and human tissues displayed elevated levels of this pro-fibrotic growth factor. CD31 (PECAM-1), a known marker for endothelial cells that plays a role in angiogenesis during endochondral bone formation [32], was also expressed in both the rat and human samples.

\section{Comparisons in protein levels and gene expression} of target molecules in rat and human traumatized tissues Tissue fibrosis and early bone matrix deposition are common features of HO formation [19-23]. To determine if fibrotic protein markers were present in the injured rat tissue, we analyzed protein samples of injured and uninjured control rat and human tissues by SDS-PAGE followed by immunoblotting. We found significantly elevated expression levels for proteins associated with tissue fibrosis, namely Fibronectin (FN), TGF- $\beta 1$, SMAD3 and PAI-1 (Fig. 7a). These elevated expression levels were very similar between the rat and human injured tissues.

As an additional way to assess whether the rat and human traumatized tissues showed similarities at the 

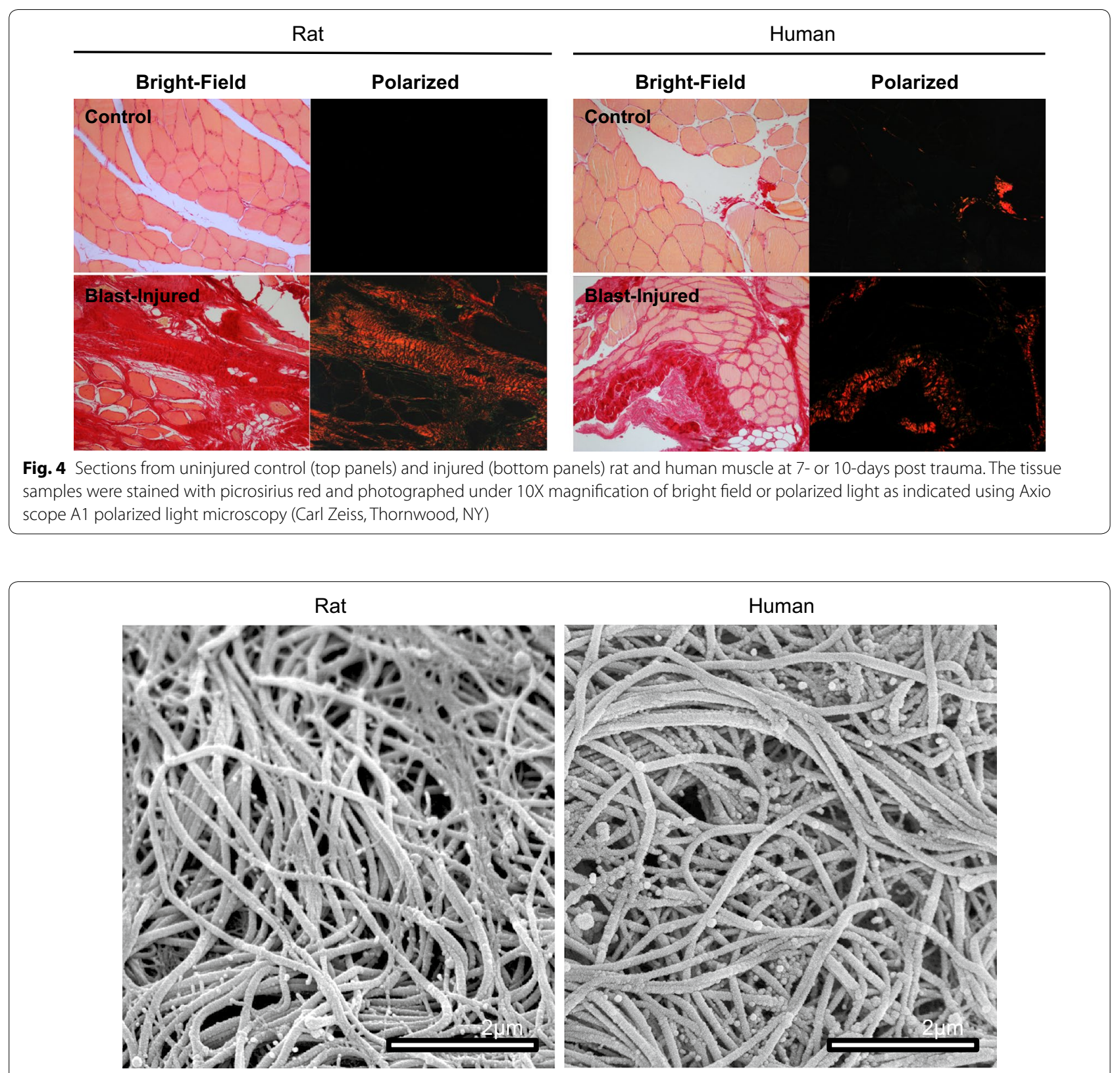

Fig. 5 Sections from injured rat (left) and human (right) decellularized muscle at 7- or 10-days post trauma. Scanning electron microscopy was performed on the samples as shown

molecular level we screened a cytokine array composed of a number of inflammatory/fibrotic markers with RNA from the traumatized muscle samples. The rat and human tissue samples showed increased expression of Activin A (ACTA), Bone Morphogenetic Protein 1 (BMP1), Bone Morphogenetic Protein 3 (BMP3) and Tumor Necrosis Factor $\alpha(T N F-\alpha)$, as shown by increased fold regulation compared to control tissue (Fig. 7b). All of these factors have been shown to be involved in the fibrotic response. Overall, our data show remarkable similarity between the rat and human early response after injury in terms of the expression of genes required for tissue fibrosis.

\section{Discussion}

Until recently, there have been few suitable animal models for post-traumatic HO. A key reason for this has been the difficulty in recapitulating the high-energy blast injuries seen too frequently in modern war-conflicts [10-14]. Most previously described animal models of $\mathrm{HO}$ are non-physiologic as they induce ectopic 

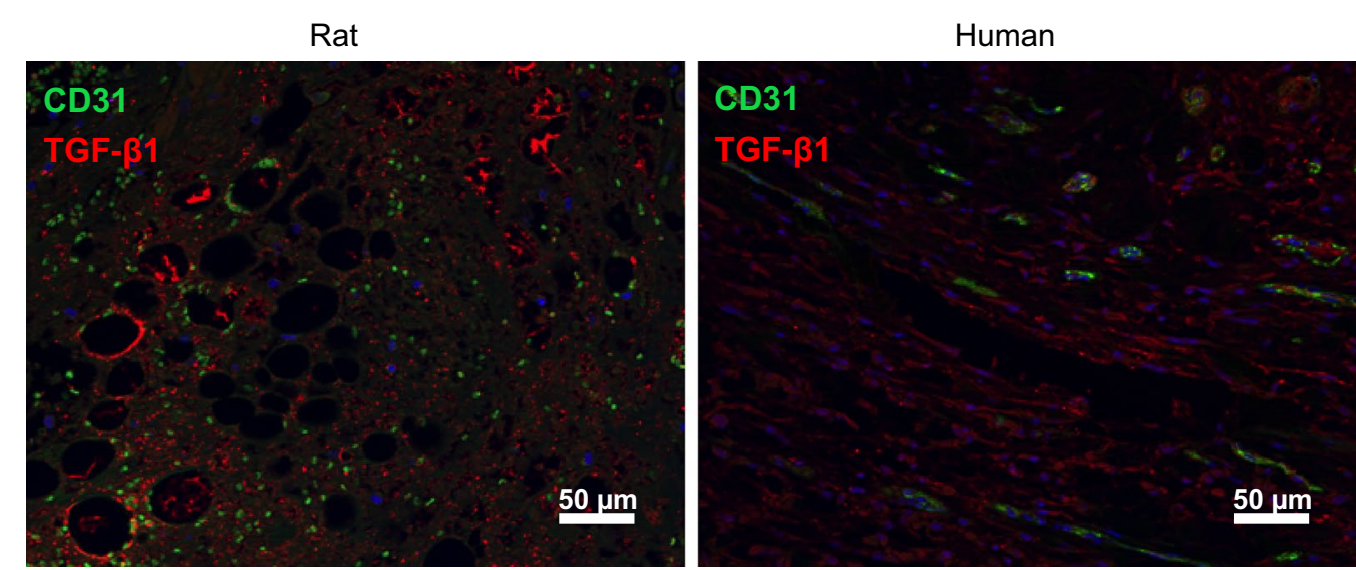

Fig. 6 Sections of injured rat (left) and human (right) muscle were processed for immnoflourescent microscopy using antibodies to either TGF- $\beta 1$ (red) or CD31 (green)

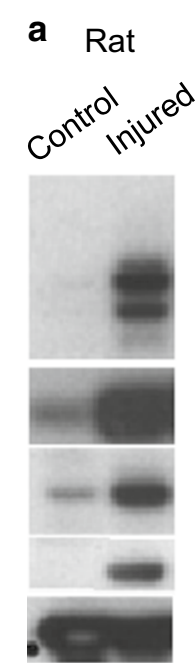

Human

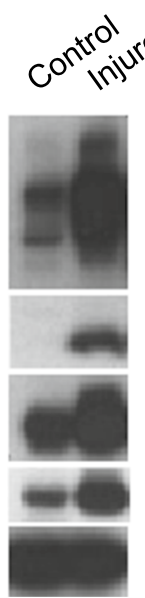

b

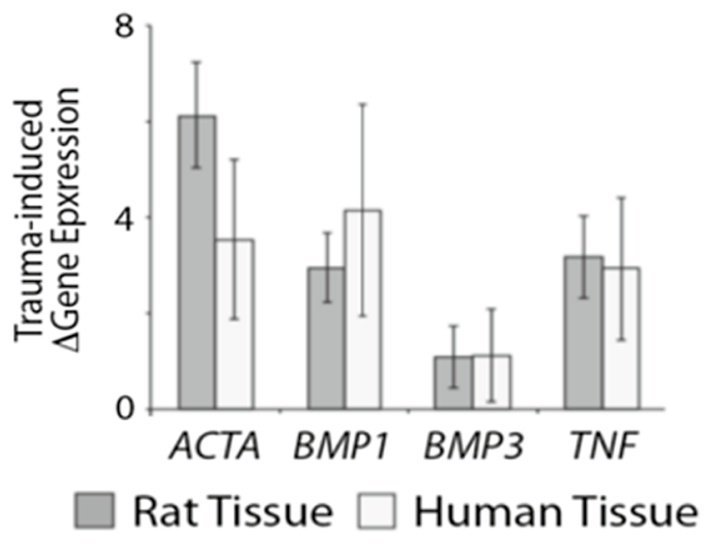

Fig. 7 a Protein extracts from rat and human uninjured control and blast trauma injured muscle tissue (Rat, 7-days; Human, 10-days HO positive patient sample) were examined by SDS-PAGE and immunoblotting with the indicated antibodies: Fibronectin, TGF- $\beta 1$, SMAD3 and PAI-1. GAPDH was used as loading control. Presented are data from one representative patient per group. $\mathbf{b}$ Rat and human tissue demonstrating increase in fold regulation compared to control tissues (error bars $=$ SD). Common cytokine PCR array was performed using RNAs from rat (7-day post-injury) and

human (10-day post-injury) muscle tissue following traumatic blast injury

bone formation through the use of exogenous agents such as bone morphogenic proteins, bone matrix, or calcium chloride $[5,19,22]$, while others induce $\mathrm{HO}$ by generating muscle damage though forced manipulation of muscle tissue or Achilles tenotomy [5, 22, 23]. These models produce $\mathrm{HO}$ with characteristics similar to that of fibrodysplasia ossificans progressiva (FOP), a genetic disease characterized by a mutation in the type I BMP receptor $A C V R 1$ [33, 34]. Importantly, while these models are very relevant to investigate the underlying molecular mechanisms of the disease and the discovery of novel targets for therapeutic interventions, they may not reflect the processes following high-energy trauma and do not explain why $\mathrm{HO}$ occurs at a uniquely high frequency after combat trauma, particularly given recent evidence that the genes involved in FOP are not up-regulated following these injuries [24]. This study is unique in that we have used a recently developed high-energy blast injury model of $\mathrm{HO}$ in rats to directly compare the molecular and cellular events in human patients who have sustained a traumatic blast injury resulting in $\mathrm{HO}$ formation. By showing a consistent cascade of early fibrotic and osteogenic events between the rat blast model and post-traumatic human 
samples that progressed to ectopic bone formation, this study provides a basis for using this animal model in additional basic/mechanistic and pre-clinical studies of post-traumatic $\mathrm{HO}$.

In particular, the utility of this rat model for posttraumatic $\mathrm{HO}$ is that it enables one to more rigorously explore the early stages of the disease following the traumatic event. As a result of the inflammation in the wound, endogenous tissue regeneration mechanisms can be overshadowed by a generalized healing response that leads to fibrosis. This early fibroproliferative response has been linked to HO [19-24, 27]. Thus, fibrosis appears to be a salient feature in the HO lesion. Additionally, repeated anecdotal surgical observations have linked areas of abundant fibrotic scarring within the wound to an increased risk of $\mathrm{HO}$ formation in humans. Fibrosis may therefore be an intermediate step in the onset of $\mathrm{HO}$ in a way that is not completely understood [19-24, 27]. For example, it is possible that regions of fibrosis convert directly to bone or that regions of fibrosis contribute osteogenic signals that drive neighboring, multipotential cells to proceed down a bone-forming pathway.

Our data show that the blast-induced $\mathrm{HO}$ in rats, as determined radiographically, occurs through the zone of injury within a similar temporal context as human blastinduced HO. The structural and ultrastructural microenvironment of post-blast tissue visualized by histology is similar in appearance between both rat and human samples. Specifically, collagen fiber orientation and size, muscle tissue destruction and intramuscular fibrosis, are parallel between the rat model and human disease. Additionally, protein analysis of rat and human tissue obtained from the blast injury site demonstrated evidence of fibrosis. This data is consistent with our group's previous findings of fibrotic precursor elements in patients who develop HO [24, 27, 31, 35]. In particular, Fibronectin, SMAD3, PAI-1 and TGF- $\beta 1$ demonstrated significantly elevated levels of protein expression in the rat and human blast injured tissue. By screening for markers of inflammatory cytokines that mediate fibrosis, it was found that $A C T A, B M P 1, B M P 3$ and TNF- $\alpha$ were elevated at the mRNA level. Importantly all of these markers of fibrosis appear to be important for the aberrant tissue regeneration pathway leading to osteogenesis [24, 27, 31, 35]. This is evident by the elevation in expression of genes needed for osteogenesis at a later time point. We found that OPN, RUNX2 and COL1A1 were elevated in both rat and human tissue at 7 - and average 10-days after blast injury. These data would indicate that the rat blast early response to injury closely parallels that of the human early response to injuries, in terms of markers for fibrosis and osteogenesis in both their temporal and spatial expression.
Blast-induced post-traumatic $\mathrm{HO}$ is associated with a variety of systemic biochemical signals that are generated to regulate the hemodynamic, metabolic and immune responses within regions of injury [31]. A likely sequence of events that occurs after injury is that activated progenitor cells within the injured muscle begin to aggregate and proliferate [27]. These cells would then provide trophic and cellular support to the regenerating tissue. A fraction of the cells then receives physical and biochemical cues to become osteoprogenitors and begin to generate ectopic bone.

\section{Conclusions}

The data presented here suggest that the early mechanisms of ectopic bone formation in both rats and humans after initial injury may follow a common pathway via an initial fibroproliferative lesion where osteoinductive, osteoconductive and osteogenic factors are present. By validating these aspects of ectopic bone formation in this trauma-induced rat, we can now more reliably use this model to identify the key events that trigger $\mathrm{HO}$ formation, and develop novel biomarkers, such as elevated levels of specific TGF- $\beta$ family members that can predict $\mathrm{HO}$ development in certain patients as well as discover and test novel targets for novel therapeutic interventions, such as inhibitors of the SMAD pathway, to prevent the formation of $\mathrm{HO}$.

\section{Abbreviations}

ACTA: activin A gene; ACVR1: activin A receptor type I; BMP1: bone morphogenetic protein 1 gene; BMP3: bone morphogenetic protein 3 gene; CD31: cluster of differentiation 31, also knows as platelet endothelial cell adhesion molecule (PECAM-1); cDNA: complementary DNA; COL1A1: type 1 collagen gene; FN: fibronectin; FOP: fibrodysplasia ossificans progressiva; FP: fibroproliferative region; GAPDH: glyceraldehyde-3-phosphate dehydrogenase; H\&E: hematoxylin and eosin; HO: heterotopic ossification; HPRT1: hypoxanthine phosphoribosyltransferase 1 gene; IHC-IF: immunohistochemistry-immunofluorescence; mg/kg: milligram/kilogram; $\mu \mathrm{m}$ : micrometer; $\mu \mathrm{g} / \mathrm{ml}$ : microgram/milliliter; NF: normal fiber; OPN: osteopontin gene; PAI-1: plasminogen activator inhibitor 1; PBS: phosphate-buffered saline; PCR: polymerase chain reaction; PECAM-1: platelet endothelial cell adhesion molecule, also knows as cluster of differentiation 31 (CD31); PFA: paraformaldehyde; PSR: picrosirius red; qRT-PCR: quantitative reverse transcription-polymerase chain reaction; RNA: ribonucleic acid; RT: reverse transcription; RUNX2: runt-related transcription factor 2 gene; SDS: sodium dodecyl sulfate; SDS-PAGE: sodium dodecyl sulfate polyacrylamide gel electrophoresis; SEM: scanning electron microscopy; SMAD3: SMAD family member 3; TGF- $\beta 1$ : transforming growth factor- $\beta 1$; TNFa: tumor necrosis factor a gene.

\section{Acknowledgements}

We thank Dr. Richard Leapman and his laboratory at the National Institute of Biomedical Imaging and Bioengineering, National Institutes of Health, for his generous support in providing scanning electron microscopy evaluation of human and rat blast tissue.

\section{Disclaimer}

The contents of this publication are the sole responsibility of the author(s) and do not necessarily reflect the views, opinions or policies of Uniformed Services University of the Health Sciences (USUHS), The Henry M. Jackson Foundation for the Advancement of Military Medicine, Inc., the Department of Defense 
(DoD), the Departments of the Army, Navy, or Air Force. Mention of trade names, commercial products, or organizations does not imply endorsement by the U.S. Government.

\section{Authors' contributions}

$L N, V P$ and $Y J$ designed experiments. YJ, ES, PJ, GC, HB, CC, TN, AR were involved in data acquisition. JFV SZ SF TJ DG CG VP and LN were involved in analysis and interpretation of the data. All authors were involved in drafting and reviewing the manuscript. All authors read and approved the final manuscript.

\section{Funding}

This work was supported by the Military Amputee Research Program at Walter Reed Army Medical Center (P05-A01 1), the Comprehensive Neurosciences Program (CNP-2008-CR01), the Defense Medical Research and Development Program (D10_1_AR_J5_920), the Congressionally Directed Medical Research Program (W81XWH-13-2-0083), the NIH Intramural Research Program (Z01 AR41131), and the USAMRAA BAA (W81XWH-17-2-0009).

\section{Availability of data and materials}

All data generated or analyzed during this study are included in the published article.

\section{Ethics approval and consent to participate}

Written informed consent was obtained from all research subjects prior to participation in this study. Approval for the research protocol and consent documents was granted by the Institutional Review Board at Walter Reed National Military Medical Center. All animal procedures were performed under approved appropriate protocols by the Institutional Animal Care and Use Committee at the University of Maryland Medical Center.

\section{Consent for publication}

Not applicable.

\section{Competing interests}

The authors declare that they have no competing interests.

\section{Author details}

${ }^{1}$ Department of Surgery, Walter Reed National Military Medical Center \& Uniformed Services University of Health Sciences, 4801 Rockville Pike, Bethesda, MD 20889, USA. ${ }^{2}$ Henry M. Jackson Foundation for the Advancement of Military Medicine, 6720A Rockledge Drive, Bethesda, MD 20817, USA. ${ }^{3}$ Department of Orthopaedic Surgery, University of Maryland Medical Center, 22 S. Green St., Baltimore, MD 21201, USA. ${ }^{4}$ Department of Orthopaedic Surgery, Medical University of South Carolina, 171 Ashley Ave, Charleston, SC 29425, USA. ${ }^{5}$ Department of Surgery, Uniformed Services University of the Health Sciences, 4301 Jones Bridge Road, Room A3008C, Bethesda, MD 20892-8022, USA.

Received: 1 March 2019 Accepted: 23 July 2019

Published online: 02 August 2019

\section{References}

1. Best TM, Hunter KD. Muscle injury and repair. Phys Med Rehabil Clin N Am. 2000;11:251-66.

2. Lieber RL, Ward SR. Cellular mechanisms of tissue fibrosis. 4. Structural and functional consequences of skeletal muscle fibrosis. Am J Physiol Cell Physiol. 2013;305:C241-52.

3. Moyer AL, Wagner KR. Regeneration versus fibrosis in skeletal muscle. Curr Opin Rheumatol. 2011;23:568-73.

4. Serrano AL, Munoz-Canoves P. Regulation and dysregulation of fibrosis in skeletal muscle. Exp Cell Res. 2010;316:3050-8.

5. Xu R, Hu J, Zhou X, Yang Y. Heterotopic ossification: mechanistic insights and clinical challenges. Bone. 2018;109:134-42.

6. Nauth A, Giles E, Potter BK, Nesti LJ, O'Brien FP, Bosse MJ, Anglen JO, Mehta S, Ahn J, Miclau T, Schemitsch EH. Heterotopic ossification in orthopaedic trauma. J Orthop Trauma. 2012;26:684-8.
7. Meyers C, Lisiecki J, Miller S, Levin A, Fayad L, Ding C, Sono T, McCarthy E, Levi B, James AW. Heterotopic ossification: a comprehensive review. JBMR Plus. 2019;3:e10172.

8. Garland DE. Clinical observations on fractures and heterotopic ossification in the spinal cord and traumatic brain injured populations. Clin Orthop Relat Res. 1988;233:86-101.

9. Garland DE, O'Hollaren RM. Fractures and dislocations about the elbow in the head-injured adult. Clin Orthop Relat Res. 1982;168:38-41.

10. Forsberg JA, Potter BK. Heterotopic ossification in wartime wounds. J Surg Orthop Adv. 2010;19:54-61.

11. Potter BK, Burns TC, Lacap AP, Granville RR, Gajewski D. Heterotopic ossification in the residual limbs of traumatic and combat-related amputees. J Am Acad Orthop Surg. 2006;14:S191-7.

12. Potter BK, Burns TC, Lacap AP, Granville RR, Gajewski DA. Heterotopic ossification following traumatic and combat-related amputations. Prevalence, risk factors, and preliminary results of excision. J Bone Joint Surg Am. 2007:89:476-86.

13. Potter BK, Forsberg JA, Davis TA, Evans KN, Hawksworth JS, Tadaki D, Brown TS, Crane NJ, Burns TC, O'Brien FP, Elster EA. Heterotopic ossification following combat-related trauma. J Bone Joint Surg Am. 2010;92(Suppl 2):74-89.

14. Melcer T, Belnap B, Walker GJ, Konoske P, Galarneau M. Heterotopic ossification in combat amputees from Afghanistan and Iraq wars: five case histories and results from a small series of patients. J Rehabil Res Dev. 2011:48:1-12

15. Liu EY, Hildebrand A, Horner NS, Athwal GS, Khan M, Alolabi B. Heterotopic ossification after total elbow arthroplasty: a systematic review. J Shoulder Elbow Surg. 2019;28:587-95.

16. Tannous O, Griffith C, O'Toole RV, Pellegrini VD Jr. Heterotopic ossification after extremity blast amputation in a Sprague-Dawley rat animal model. J Orthop Trauma. 2011;25:506-10.

17. DE Jaffe YD, Blevins J, Gasbarro G, Hughes T, Paryavi E, Nguyen T, Fourney WL, Pellegrini VD Jr. Does blast medium affect heterotopic ossification in a blast-amputation model? Clin Orthop Relat Res. 2015;473:2680-7.

18. Robertson ADCA, Nguyen TP, Jaffe DE, Holmes RE, Hanna EL, Rhee JG, Barfield WR, Fourney WB, Stains JP, Pellegrini VD. Failure of indomethacin and radiation to prevent blast-induced heterotopic ossification in a Sprague-Dawley rat model. Clin Orthop Relat Res. 2019;477:644-54.

19. Koolen PG, Schreinemacher MH, Peppelenbosch AG. Heterotopic ossifications in midline abdominal scars: a critical review of the literature. Eur J Vasc Endovasc Surg. 2010;40:155-9.

20. Medici D, Kalluri R. Endothelial-mesenchymal transition and its contribution to the emergence of stem cell phenotype. Semin Cancer Biol. 2012:22:379-84.

21. Medina A, Ma Z, Varkey M, Liu H, Iwashina T, Ding J, Tredget EE. Fibrocytes participate in the development of heterotopic ossification. J Burn Care Res. 2015:36:394-404.

22. Tredget EE, Levi B, Donelan MB. Biology and principles of scar management and burn reconstruction. Surg Clin N Am. 2014;94:793-815.

23. Uezumi A, Ikemoto-Uezumi M, Tsuchida K. Roles of nonmyogenic mesenchymal progenitors in pathogenesis and regeneration of skeletal muscle. Front Physiol. 2014;5:68.

24. Jackson WM, Aragon AB, Onodera J, Koehler SM, Ji Y, Bulken-Hoover JD, Vogler JA, Tuan RS, Nesti LJ. Cytokine expression in muscle following traumatic injury. J Orthop Res. 2011;29:1613-20.

25. Livak KJ, Schmittgen TD. Analysis of relative gene expression data using real-time quantitative PCR and the 2(-Delta Delta $C(T))$ method. Methods. 2001;25:402-8.

26. Grimm PC, Nickerson P, Gough J, McKenna R, Stern E, Jeffery J, Rush DN. Computerized image analysis of Sirius Red-stained renal allograft biopsies as a surrogate marker to predict long-term allograft function. J Am Soc Nephrol. 2003;14:1662-8.

27. Jackson WM, Lozito TP, Djouad F, Kuhn NZ, Nesti LJ, Tuan RS. Differentiation and regeneration potential of mesenchymal progenitor cells derived from traumatized muscle tissue. J Cell Mol Med. 2011;15:2377-88.

28. Almeida HL Jr, Monteiro L, Marques e Silva R, Rocha NM, Scheffer H. Scanning electron microscopy of a blister roof in dystrophic epidermolysis bullosa. An Bras Dermatol. 2013;88:966-8.

29. Chen X, Nadiarynkh O, Plotnikov S, Campagnola PJ. Second harmonic generation microscopy for quantitative analysis of collagen fibrillar structure. Nat Protoc. 2012;7:654-69. 
30. Grover GN, Rao N, Christman KL. Myocardial matrix-polyethylene glycol hybrid hydrogels for tissue engineering. Nanotechnology. 2014;25:014011.

31. Ji Y, Christopherson GT, Kluk MW, Amrani O, Jackson WM, Nesti LJ. Heterotopic ossification following musculoskeletal trauma: modeling stem and progenitor cells in their microenvironment. Adv Exp Med Biol. 2011;720:39-50.

32. Medici D, Shore EM, Lounev VY, Kaplan FS, Kalluri R, Olsen BR. Conversion of vascular endothelial cells into multipotent stem-like cells. Nat Med. 2010;16:1400-6.

33. Kaplan FS, Pignolo RJ, Shore EM. The FOP metamorphogene encodes a novel type I receptor that dysregulates BMP signaling. Cytokine Growth Factor Rev. 2009;20:399-407
34. Shore EM, Kaplan FS. Insights from a rare genetic disorder of extraskeletal bone formation, fibrodysplasia ossificans progressiva (FOP). Bone 2008:43:427-33.

35. Kluk MW, Ji Y, Shin EH, Amrani O, Onodera J, Jackson WM, Nesti LJ. Fibroregulation of mesenchymal progenitor cells by BMP-4 after traumatic muscle injury. J Orthop Trauma. 2012;26:693-8.

\section{Publisher's Note}

Springer Nature remains neutral with regard to jurisdictional claims in published maps and institutional affiliations.
Ready to submit your research? Choose BMC and benefit from:

- fast, convenient online submission

- thorough peer review by experienced researchers in your field

- rapid publication on acceptance

- support for research data, including large and complex data types

- gold Open Access which fosters wider collaboration and increased citations

- maximum visibility for your research: over 100M website views per year

At BMC, research is always in progress.

Learn more biomedcentral.com/submissions 